\title{
Industry applications for adopting value engineering in construction: A study from general contractors' perspective
}

\author{
Gulbin Ozcan-Deniz *1 iD, Carolina Ramirez ${ }^{1}$ iD \\ ${ }^{1}$ Thomas Jefferson University, Construction Management, Philadelphia, PA, USA
}

\begin{abstract}
Value engineering (VE) has been widely used in a variety of industries to analyze the function of systems and services to provide the best value for the money spent while maintaining a qualified product. It has been common to use VE in construction projects, majorly in an attempt to achieve cost savings. Considering the know-how and resources required to set up a proper VE system, construction companies have been evaluating their resources to decide whether or not to implement VE. This study aims to analyze the most common reasons why and how General Contracting (GC) companies implement VE and understand whether VE improves collaboration and efficiency in the construction process. The methodology includes reviewing local case studies to understand the VE processes from GC companies' perspectives with strengths and weaknesses. Results of this study identified the most common reason to adopt VE as cost savings, as expected. The secondary reasons were identified as life cycle savings, added value to the company, and better collaboration with the design team, which emphasized that VE is expected to improve collaboration and efficiency. This study contributes to the VE body of knowledge by presenting why and how GC companies should implement VE by emphasizing project performance success parameters. The results highlighted that, although the cost savings mainly were less than $25 \%$, the majority of the companies believed that VE had improved both collaboration and efficiency in their construction projects.
\end{abstract}

\section{Keywords}

Value engineering; Construction; General contracting; Case study

Received: 28 October 2021; Accepted: 20 December 2021

ISSN: 2630-5771 (online) (C) 2021 Golden Light Publishing All rights reserved.

\section{Introduction}

Value engineering (VE) is a method that focuses on performing essential functions of a job better while achieving the same required end product. This technique requires a group of people to work together, usually in the design stages of a project, to come up with creative ways to improve the end value of a project [1]. World War II is where VE first started with the innovations from the industrial community. During WWII, material shortages forced industries to use substitute materials in production. The General Electric Company was asked to increase their production of turbosuperchargers by 20 times more. They were producing 50 per week and had to increase to 1,000 turbo-superchargers per week. In addition, armament parts were in great demand. With all of this demand, Mr. Lawrence D. Miles was given the task of finding "a more effective way to improve a product value" [2]. Mr. Miles combined various ideas and techniques to develop an organized approach to achieve the same value of a product [3]

\footnotetext{
* Corresponding author

Email: Gulbin.Deniz@jefferson.edu
} 
In doing so, Mr. Miles found that indeed there were ways to substitute items while giving the same or even better performance as the original in their products. This is the mindset of VE, and it is the same thinking that is replicated today.

VE has been a practice for over sixty (60) years, yet companies are not fully convinced why and how VE should be implemented in construction projects. This study aims to reveal the common VE implications in the construction industry with their reasons and performance results. Case studies are used to investigate whether VE improves collaboration and efficiency in construction projects. Findings include potential strengths and weaknesses of previous construction projects to support the application of VE for Construction Managers and General Contracting (GC) companies.

\section{Background of value engineering}

As mentioned before, VE was launched by the General Electric Company in 1947 in an effort to improve product efficiency with an organized approach to develop less costly alternatives while ensuring value in a product. The methodology of VE is a structured process called a Job Plan. There are five phases in the Job Plan, as (1) Information Phase, (2) Function and Creative Phase, (3) Evaluation/ Analytical Phase,

Development/Recommendation Phase, and (5) Report Phase [1]:

- The information phase is about defining the research topic or identifying the problem. All team members are familiar with the present state of the project and participate in functional analysis to determine the areas of high and low costs [4].

- The creative phase involves gathering information that can improve the end value or the process. This stage includes brainstorming and developing alternatives with more costeffective ways for the project.

- The evaluation phase is about how the information found can be implemented. The team evaluates and ranks ideas and focuses on higher-ranked ideas. The purpose is to find and prioritize the most significant ideas in this phase [5].

- The report phase is about gathering the information found and presenting them in an adequate format for the audience. A formal VE proposal is created, and the best alternatives selected in the previous phase are included here.

- The methodology process is designed to help find ways to work better to complete the function at hand. The selected alternative is implemented in this phase.

There are benefits to VE that are important to notice. One of these benefits is that technology is constantly improving, and new materials are available to produce a greater product value more effectively. Older criteria can include materials that are more expensive, require more labor to set up, or are just inefficient compared to the newer criteria available [6]. Another benefit to VE is that problems solved in the design process can save a considerable amount of money compared to fixing the issue during the construction phase. With this process, a project's risk of becoming over budget is diminished. Another benefit is that the VE conducted in one project cannot just benefit one project. The findings can be used to lower costs or use more efficient materials in similar projects the company has. Clearly, VE helps lower cost, find more efficient methods and materials, reduce risk, and be used across many projects. With these benefits, VE stands out to be an ultimate add-on to the projects of any company, as it is expected to pay off its initial setup at the end.

There are a couple of reasons that could impact the effectiveness of VE. For example, during the process of VE, it is essential to conduct adequate research to make sure VE implications will result in being as effective as planned. When there is not enough research conducted for the VE process, it is not possible to have a more or less complete information database. With the lack of an information database, people tend to make decisions based on their gut feelings rather than reviewing the facts [7]. VE is about finding creative ways to improve the end value of a project. The end value is measured within the different phases in the 
process of VE so that the improvements in the end value will be clear when research is done throughout the process. VE includes creativity, which can also lead to another issue of finding the most feasible way to improve [7]. The lack of creativity can limit the possibilities of choosing among the best methods for the project to improve the end result. As mentioned before, VE requires different people to get together and find alternative ways to improve the product's value. For VE to function appropriately, different ideas need to be heard and taken into consideration. There has to be a team that collaborates and works together to achieve the best result possible. VE is all about teamwork, creativity, and a considerable amount of continuous research. If a VE process lacks one or the other, VE implications will not be as effective as planned and could potentially waste time and money.

\section{Value engineering in construction}

VE gained interest in the construction industry in 1972. The Society of American Value Engineering decided to emphasize VE in their 12th annual conference in the construction industry [8]. At the conference, many architects, engineers, contractors, and other industry members were attentive to how VE would benefit their future projects. Over the years, VE has proven itself to be a method that reduces costs in the construction industry.

Many researchers have studied VE in the construction industry. A previous study focused on implementing VE in a residential building and stated that VE could be applied to any stage of a project's design development cycle [1]. In the end, they found that the most significant benefits and resource savings typically occur early in the development and conceptual design stages. Another study focused on motorway construction in Croatia, where both time and cost savings were achieved with VE [9]. With VE implications, around \$43M and 12 months were saved, equivalent to $6 \%$ financial savings and $17 \%$ project duration reduction. Another study of VE application in road construction utilized the Pareto Law 20/80, which states that around $20 \%$ of the functions constitute about $80 \%$ of the cost [10]. The results showed that $23.07 \%$ of the functions formed $73.3 \%$ of the cost, and thus, the VE analysis and study were controlled by the first three out of thirteen analyzed.

VE was also applied in commercial building projects [11]. They studied VE application to various alternatives in planning, creation of design and specifications, and use of locally available materials to minimize the construction as much as possible without decreasing the overall quality of the project. A recent study combined VE with Building information modeling (BIM) to develop, understand project elements, and identify suitable design alternatives [12]. The study resulted in a total cost reduction of $31 \%$ to $48 \%$ without a change in the functional properties of the structural elements by using BIM and VE together. Similarly, VE was defined as one of the best techniques to identify unnecessary costs without adversely affecting quality. A previous study discussed the effective implementation of VE in cement concrete road projects by applying Pareto's law [13]. The results showed direct cost savings for the project.

How VE was perceived by construction practitioners vs. how it was applied in the industry was analyzed via a survey questionnaire [14]. The results showed that most of the survey participants neither understood nor performed the actual concept of VE, even in the projects that had implemented VE. The literature view also showed studies that concentrated on VE applications used by GC firms during various project phases. Atabay and Galipogullari [9] focused on the VE process during the project preparation and revision phases and emphasized the importance of working systematically to use VE among the local construction industry. Other studies in developing countries, like one in Saudi Arabia, worked on helping GC companies to select the most effective subcontractor alternative by using VE [15]. Another study from India focused on road contractors and applied VE specifically to reduce costs [16]. The study revealed that VE could be used during any stage of construction, but earlier, the better for contractors, as expected. A study from Oman looked at VE applications for contractors 
from a sustainability perspective and proposed incorporating VE to initiate sustainability measures [17]. Their study found out that VE could be used to boost sustainable economic development alternatives in developing countries. A research from Libya focused on the perceived impact of adopting VE by contractors and presented that VE adoption in Libya requires better understanding and support from various stakeholders [18]. Another study drew attention to the VE applications in the Polish construction industry and revealed that the level of knowledge about value engineering was still low locally [19]. Previous studies indicate that VE has not been actively used by construction companies, even those that adopted its process.

VE focuses on balancing time, people's ideas, and money. The construction industry is a perfect example of such, as projects have to be completed on time or under the schedule to make more profit with the best quality produced. In the construction industry, there are many careers with different perspectives on how a project should be developed. Combining these different perspectives, VE can create new ways to improve the value of the end product with better-qualified materials and less cost. The overall, VE process aims for an improved value of an end product, and the key to finding the best result is to complete the Job Plan in order as a team. This study will evaluate VE in construction projects in relation to the reasons of application, performance results, and collaboration and efficiency within construction project parties to see common paths on how the VE adaptation process can be improved in GC companies.

\section{Methodology}

The steps of the methodology used for this study are given in Fig. 1. The process started by researching the steps for VE implementation and how it was implemented in the construction industry in particular. After completing the research, a literature review database was created and used to develop a survey. The survey consisted of general questions of the company's VE system and specific questions of reasons and benefits of using VE in their projects. General questions were related to how often VE was used in the company, the types of projects (residential, commercial, etc.) that the company utilized VE, their VE guidelines (if any), and VE training. Specific questions included details about the amounts of projects using VE, why they were using VE in the first place, and how VE improved project performances. This survey was updated considering the list of GC companies that were prospects of being interviewed. The survey was then used to interview representatives from the GC companies, and the data was collected.

During these interviews, participants from GC companies in the North-East U.S. area (e.g., PA, DE, NY, etc.) were asked whether VE had improved collaboration and efficiency in the company and what percentage of cost savings were achieved related to VE. Table 1 presents a sample of the companies interviewed with their location and project type information. A few participants with various roles, such as Director of Operations, Chief Estimator, Assistant or Senior Project Manager, Project Manager, and Project Director, were selected to be interviewed from fifteen GC companies in the area.



Fig. 1. Steps for assessing VE practices in construction 
Table 1. Company Information

\begin{tabular}{lll}
\hline Company & Location & Project Types \\
\hline Company A & West Chester, PA & Higher Education \\
Company B & Bensalem, PA & Commercial, Higher Education, Healthcare, Residential \\
Company C & Conshohocken, PA & Residential \\
Company D & Ambler, PA & Commercial, Higher Education, Interiors \\
Company E & East Petersburg, PA & Commercial, Higher Education, Healthcare, Residential \\
Company F & Philadelphia, PA & Commercial, Higher Education, Healthcare, Residential, \\
& & Multi-Family, Hospitality, Retail, Interiors \\
Company G & Bethlehem, PA & Commercial, Higher Education, Healthcare, Residential, \\
& & $\begin{array}{l}\text { Multi-Family, Hospitality, Retail, Interiors, Mixed Use, } \\
\text { Transportation }\end{array}$ \\
Company G & Newark, DE & Commercial, Higher Education, Healthcare, Residential, \\
& & $\begin{array}{l}\text { Multi-Family, Hospitality, Retail, Interiors, Mixed Use, } \\
\text { Transportation }\end{array}$ \\
Company H & Philadelphia, PA & Commercial, Higher Education, Healthcare, Residential, \\
& & Multi-Family, Hospitality, Retail, Interiors, Mixed-Use \\
Company H & New York, NY & $\begin{array}{l}\text { Commercial, Higher Education, Healthcare, Residential, } \\
\text { Multi-Family, Hospitality, Retail, Interiors, Mixed-Use }\end{array}$ \\
& &
\end{tabular}

This process permitted to have multiple responses from the same company. The interview allowed participants to respond to an open-ended section to state the strongest and weakest aspects of their VE program. Each company answered questions related to several projects that they had utilized VE at the time. A total of thirty-two data points was collected and analyzed. This part was specifically important for this study to understand the VE processes with strengths and weaknesses from GC companies' perspectives. The reasoning behind implementing VE practices in construction projects and their impact on improving collaboration and efficiency were discussed with participants.

In the next step, the data was sorted out and analyzed to rank interviewees' responses. Among the companies surveyed, only $87 \%$ of them were actively used VE, so the responses from multiple participants in these companies were filtered. Common responses were marked once all of the data was sorted and analyzed. The data were analyzed collectively to develop practices that can benefit the construction industry as a whole. Best practices of implementing VE in construction projects and how specifically GC companies adopted these practices in their companies were identified. Results will be presented in the next session.

\section{Results and discussions}

As mentioned before, VE is a relatively new concept in the construction industry. This was reflected in the survey results, as only $40 \%$ of the GC companies have always been practicing VE. $27 \%$ of the companies were utilizing VE usually, and $13 \%$ were occasionally practicing. The types of construction projects where VE was frequently used were marked as low-rise and high-rise commercial building projects (Fig. 2). They were followed by residential construction and infrastructure projects. Other types of projects, which seldomly use VE, are mentioned as interior fit-outs, retail construction, such as warehouses, train stations, train depots, etc. As it can be observed from the figure, respondents were allowed to mark multiple projects, and overall, GC companies main project scope stayed in superstructure projects and commercial buildings. 


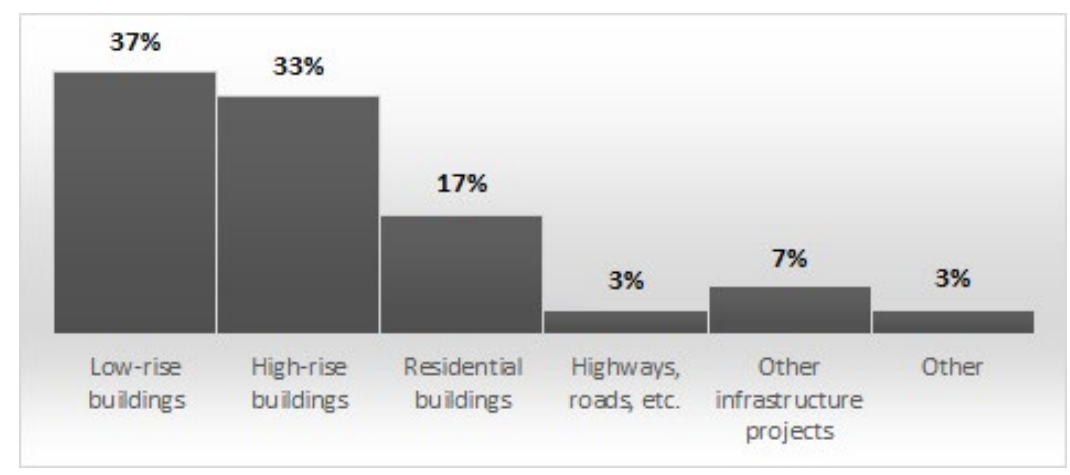

Fig. 2. Types of construction projects using VE practices

Respondents were also asked about the percentage of projects that implement VE in their companies. The results were collected in ranges of $25 \%$ as given in Fig. 3. $14 \%$ of the respondents mentioned that all projects in their companies use VE, while the highest-ranking of responses (43\%) showed that 75 to $100 \%$ of projects in the GC companies utilize VE. As all of the companies surveyed were using VE, it is worth mentioning that $21 \%$ of the companies were only using VE in 0 to $25 \%$ of their projects, which implied that they were not using VE actively.

When respondents were asked about defined policies or guidelines for VE in their companies, the results were very interesting. The majority of the GC companies (92\%) mentioned that they do not have any defined VE guidelines, and $8 \%$ stated they were unsure whether there were any VE guidelines. Although $40 \%$ of the GC companies have always been practicing VE, even the majority of them did not have any principles for VE implementation or practice. In a related sense, companies were asked about their VE training. As expected, after their previous answers, only $8 \%$ of the companies had VE training, and $69 \%$ mentioned that there was no training. The rest of the respondents $(23 \%)$ were unsure whether there was any VE training in their company or not.

One of the purposes of this research is to find out why GC companies implement VE. To collect this data, respondents were given a list of VE benefits from previous research and asked to select all reasons their company believes in implementing
VE. The last portion was left as 'other' to allow participants to state additional reasons. GC companies' reasons to use VE are given in Fig. 4. According to the results, the majority of the companies $(80 \%)$ are using VE to achieve cost savings, which is also linked to life cycle savings of $53 \%$. This result is in line with the literature findings. As stated in a recent study [9], Ve implementations in more complex and larger projects yield a high potential for cost savings. Improving the company and the company image seems to be the second reason for implementing $\mathrm{VE}$, as reasons for 'added value to the company' and 'be competitive in the market' were selected by half of the respondents. 'Keeping up with the advances' is another reason to implement VE. It will eventually improve the company's image and value-added to the company while making it more competitive in the market.

In this study, VE was expected to improve collaboration and efficiency in GC companies. Reasonimplye VE implies that half of the companies have used VE to collaborate better with the design team. Less common reasons to utilize VE were found as VE being mandatory to be used in specific projects or with certain owners, companies' or owners' interest in using VE, and changes in the end user's agreements throughout the project. Respondents did not add any reasons to use VE in their companies, so it can be concluded that the reasons to use $\mathrm{VE}$ found in previous research were accurate. 




Fig. 3. Percentage of projects utilizing VE

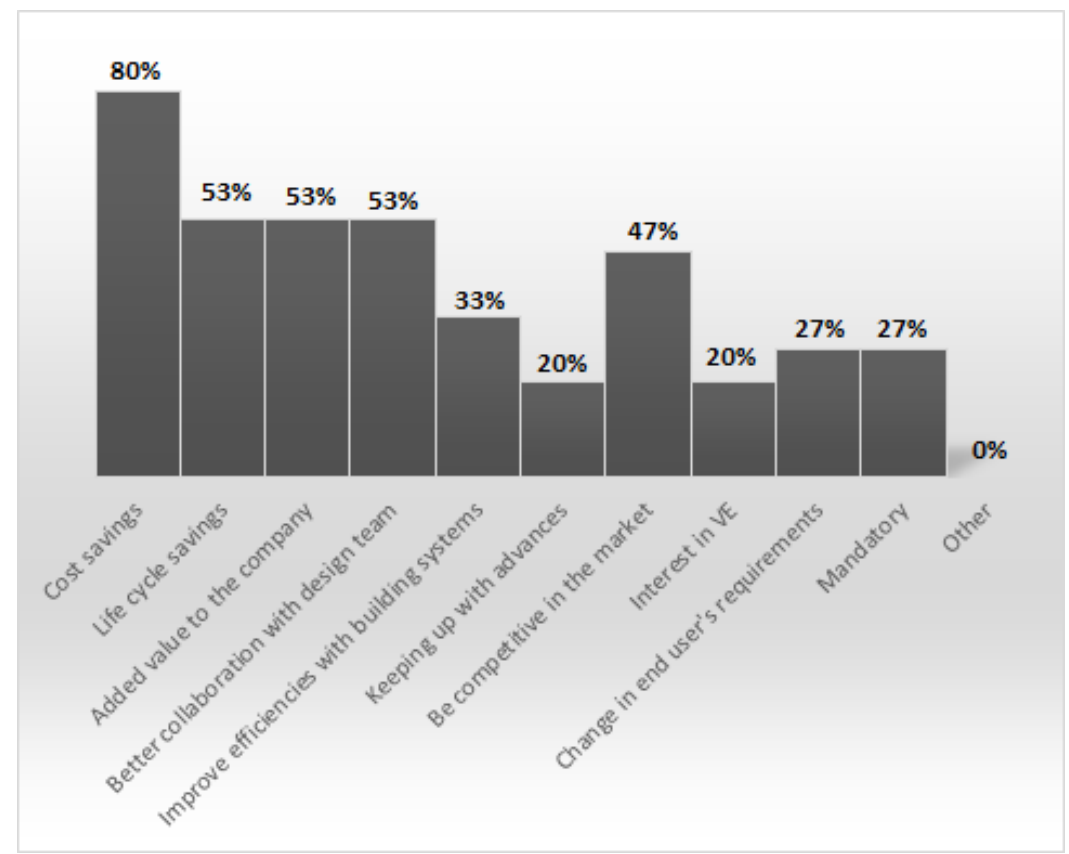

Fig. 4. Percentage of reasons to use VE

Data explicitly collected related to collaboration and efficiency revealed that $69 \%$ of respondents believed that VE had improved both collaboration and efficiency of projects in their company. This result is in line with the literature findings. A previous study [15] emphasized the importance of team effort in affecting the outcomes of a planned VE process. On the other hand, $15 \%$ of the respondents were unsure whether VE improved either, and $8 \%$ stated that VE did not improve collaboration or efficiency. It is important to interpret these results with the results related to VE utilization reasons. Although half of the respondents ( $53 \%$ to be accurate) stated that their company used VE to improve collaboration with design teams, much more of the respondents mentioned that VE improved collaboration in the actual projects upon its successful implementation. The same situation happened with the efficiency. $33 \%$ of the companies used VE to improve efficiency, while actually efficiency was improved around $69 \%$ in construction projects. Under these circumstances, it is safe to state that $\mathrm{VE}$ implementation has been more successful than expected in improving construction project parties' collaboration and projects' efficiencies.

When discussing how VE improves collaboration and efficiency in companies, it was 
also asked how companies were measuring the performances of their projects. As presented in Fig. 5 , there was a range of criteria used. Half of the respondents stated that they were using qualitative measurements, while one-third (around 33\%) indicated that they were using quantitative measures. When companies were asked for sample methods, and details for the 'Other' category selected, items such as monthly performance measures, timeliness on projects, being within budget on projects, client satisfaction, and recommendations for future jobs were mentioned. As it can be observed, especially the last two items, client satisfaction, and recommendation, are qualitative performance parameters, which are very hard to measure. Respondents stated that these qualitative items were used in connection with the quantitative measures, as expected, and VE's implications on all can be evaluated.

Remembering that $43 \%$ of companies showed that 75 to $100 \%$ of projects have been utilizing VE, respondents were asked about the average ranges of cost savings experienced in construction projects precisely due to the use of VE. In this sense, 15\% of the respondents were unsure about the actual cost savings, and $15 \%$ stated that the cost savings were between 25 to $50 \%$ due to VE. The majority, $69 \%$, of the respondents mentioned that they experienced up to $25 \%$ cost savings with VE implementation in their projects. Even up to $25 \%$ cost savings is a major project performance improvement for especially mid-to-large scale construction projects. The results validate that VE not only improves collaboration but also helps projects to save on final costs.
In this sense, it becomes extremely important to know how to implement VE with its strengths and weaknesses. To learn how GC companies successfully manage their VE implications, respondents were asked about the strengths and weaknesses of their companies' VE programs. The weak points of VE implementation included owners following traditional architects and not prioritizing VE in projects. Additionally, in companies, VE was incorrectly thought to be costly and timely by traditional mindsets. Respondents from such companies stated that they had challenges managing VE programs successfully. In such traditional settings, some parties insisted on taking the traditional approaches, which would have resulted in increased costs. Some weaknesses revealed lessons learned and items that needed to be overcome before implementing VE in construction projects. For example, it was stated that a clear communication path for VE changes and VE guidelines is needed throughout the process. When parties know the impact of VE in the project outcomes and VE implications are selected carefully to fit other project requirements, VE implications have had the most success in GC companies. These findings support the aim of this study is proposing whether VE improves collaboration and efficiency in the construction process, as it is seen that VE enhances collaboration, and in exchange, successful collaboration improves VE practices and project success.

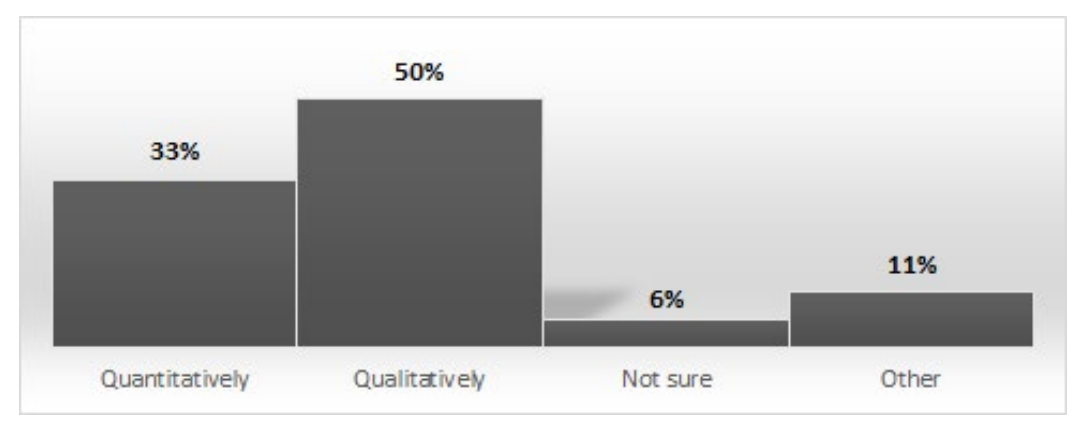

Fig. 5. Project performance measuring criteria 
Some differences in-between how GC companies implement VE in different project types were also observed. Practitioners struggled to stay in with allocated funding guidelines in publicly funded projects. Since the funding allocation was based on a yearly budget, VE decisions had to wait until the beginning of the fiscal year. The public funding also affected the selection of materials and subcontractors, as all bidding was made based on the lowest bidder selection. When VE was used during the project's life-cycle, different department managers needed to be involved. It was challenging to oversee all aspects of the project, as weekly meetings were required to decide on the best material and vendor options. The VE use in interior fit-out projects was more focused on higher cost savings and improving collaboration with designers. It was an expected statement considering that interior fit-out projects have detailed finishes, which is a potential area to implement VE ideas and improve collaboration among interior design and GC parties.

Many of the companies emphasized that the approach to VE is primarily based on the project team. In companies where VE was implemented successfully, the project operated somewhat autonomously. The project team had the ability to manage the project to produce more value for the company. These companies were keen to incorporate new industry standards in their core system when these new standards were proven to increase the value of their projects, as well as their companies.

When companies were asked about the strength they have experienced due to VE implications; the general idea was that VE brings various options and savings with quality. Some of the companies used in-house fabrication, which helped with the successful substitution of materials. Others stated that VE requires minimal investment yet brings in new ideas in design. One of the strengths of VE was mentioned as improving communication and collaboration with design parties and eventually increasing the Owner's value of the building.
To sum up, best practices of VE by GC companies can be summarized in five main subject areas:

1) VE Program Management and Impact on Project Success: The results of this study showed that GC companies' understanding and acceptance of VE parameters have a considerable effect on the success of increasing the value of the project as a product. Respondents in large GC companies mentioned that upper management and the Owner supported VE and the program management involved continuous monitoring of project success parameters, such as cost and schedule impacts of VE. In this case, best practices include adopting a holistic approach in integrating VE fully with the Project Management, Owner, and Designer Teams and sustaining quarterly reports in project performances.

2) Proper Composition of VE Teams: In successfully implemented GC companies, VE team members take responsibility for $\mathrm{VE}$ decisions, as well as the outcomes and the ultimate success of the VE process. For this purpose, teams should be created at the beginning of the project by following specific steps to get team members acquainted with the project scope and functions, VE content, and each other. Successful VE implementations have shown that team members evaluated ideas together by rating different concepts regardless of team members' areas of expertise.

3) VE Training: Many companies with successful VE implementation offered VE training at parties. Some other companies mentioned that the lack of VE training and education caused parties to freeze at specific points of the VE implementation in the project, as they were not sure how to proceed. In this sense, comprehensive VE training should include an introduction to the VE concept, applications of VE with examples of VE misconceptions, why $\mathrm{VE}$ is implemented in construction projects, and how to use VE change proposals. Attendees should understand what VE is, how it is 
performed, and why it is essential before applying it to the project in question. It is also important to emphasize the importance of teamwork regarding how to increase the value of the project parameters.

4) Implementing VE over Project's Life-cycle: Respondents agreed that VE could be observed in all phases of the construction project lifecycle while emphasizing that it is mainly used in planning, design, and construction. To achieve the best value of the project, it is suggested to start with the Charette Process, where participants are already trying to generate alternatives to project parameters. During the Planning and Design Phases, life-cycle costing (LCC) can be used to evaluate alternatives with their potential cost implications on the project. GC companies have more input in the design phase alternatives in design-build projects as expected. During construction is the time where GC company would have more saying on the alternatives to proposed substitutions of the required materials and methods. In the holistic approach suggested, all parties' inputs are suggested to be included to implement VE over different project phases.

5) VE Implementation Phase by the GC Company: Respondents agreed that the success of the VE implementation lies not only in the company parameters but also in the contract. Contractors are suggested to check the VE clauses and the Alternates sections to make sure they have all VE terms in hand. If companies are using design-build delivery methods, the amount of information available to the GC VE team beforehand was reported to affect the success of VE implementation. In this case, both the contract settings and the delivery methods were found to impact the VE implementation and the success of project parameters.

\section{Conclusions}

This study analyzed how and why the GC companies in the North-East U.S. area have been implementing VE in construction projects. As expected, VE was implemented to achieve better cost savings, which also included life cycle savings for the projects, as well as adding value to the company. Additionally, many of the companies mentioned that the Owner required the use of VE, which was one of the most common reasons they implemented VE in the first place. The results showed that companies' or owners' interest in using VE had increased VE implementation in construction projects.

Another aspect of VE implementation evaluated in this study was to understand whether VE improves collaboration and efficiency in the construction process. The results indicated a definite correlation between VE use and the improvement of collaboration with design teams. The actual efficiency was improved by around $70 \%$ among the case studies collected. This considerable percentage indicates that VE implications have had success in GC companies, whether they were implemented due to Owners' requirements or the preference of GC companies.

The strengths and weaknesses of VE implementations among GC companies revealed that traditional project delivery methods and mindsets do not work with the philosophy of VE. Some companies used lessons learned from past experiences to suggest improved ways of handling traditional project relationships, such as setting a clear communication path to resolve issues and focusing more on collaboration among parties. Others were not that lucky and definitely stated the need for VE guidelines, which were missing in their company at the time of the VE implementation. The strengths of VE have lied within the savings in terms of cost and time while achieving the same or better quality, which is, in fact, directly supporting the philosophy of VE. Additional strengths of VE were mentioned as obtaining the new point of view to current designs and improving collaboration, which was a key factor for this study in checking VE implementation in construction projects.

Overall, the findings indicated that VE had been widely used by GC companies, yet not all companies had set a system or guidelines for its implementation. The benefits of VE implementation were evident to all companies, 
though some respondents were not happy to debate VE with traditional mindsets. Still, the VE implementation is expected to keep up its pace in the construction industry, mainly due to the fact that VE can improve collaboration and efficiency of construction projects upon proper use and implementation. Therefore, future studies are planned to expand the case study database within and outside the North-East U.S. and eventually develop a guideline for successful implementation of VE in GC companies. These future studies are planned to focus on VE implementation in subcontractor companies. Collecting data from subcontractor companies will help analyze the VE understanding and process in specific construction work areas and allow comparing GC vs. subcontractor VE applications.

\section{Declaration of conflicting interests}

The author(s) declared no potential conflicts of interest with respect to the research, authorship, and/or publication of this article.

\section{References}

[1] Chougule, A, Gupta, AK, Patil, S (2014) Application of value engineering technique to a residential building - Case Study. International Journal of Innovative Research in Advanced Engineering (IJIRAE) 1(12): 115-118.

[2] Mukhopadhyaya, AK Value Engineering Mastermind: From Concept to Value Engineering Certification, Response Publications, Los Angeles, CA, 2009.

[3] Cooper, R., Slagmulder, R. Target Costing and Value Engineering, Portland, OR: Productivity Press, 1997.

[4] Najafi, H, Abbas, YA, Nahavandi, H (2010) Value engineering and its effect in reduction of industrial organization energy expenses. International Journal of Economics and Management Engineering, 4(2): 68-74.
[5] DOD. Value Engineering Handbook, Institute for Defense Analysis, Alexandria, VA, 1986.

[6] Mitten, D (1997) Benefits of value engineering criteria studies. AACE International Transactions: Morgantown: 331-332.

[7] Belokar R, Sharma A. Achieving success through value engineering: a case study. World Congress on Engineering and Computer Science, 24-26 October 2012, San Francisco, USA.

[8] Loveless B. K. Value Engineering in the Construction Process, 1986.

[9] Atabay S, Galipogullari, N (2013) Application of value engineering in construction projects. Journal of Traffic and Transportation Engineering, 1(1): 39-48.

[10] Dhalyalkar S, Ahire H (2016) Application of value engineering in road construction project. Imperial Journal of Interdisciplinary Research, 2(11): 101104.

[11] Rane N, Attarde P (2016) Application of value engineering in commercial building projects. International Journal of Latest Trend in Engineering and Technology, 6(3): 286-291.

[12] Taher A, AbdElRadhid I, Elbeltagi E (2019) Integration of building information modeling with value engineering in construction industry-Case Study. International Journal of Basic and Applied Sciences, 8(4): 75-82.

[13] Mehta C, Mehta P, and Pitroda J (2020) Application of value engineering in construction projects. International Research Journal of Engineering and Technology (IRJET) 7(7): 433437.

[14] Mansfield S, Udo-Inyang P (2006) Application of value engineering within the construction industry. 42nd Annual Conference, 20-22 April 2006, Colorado State University Fort Collins, Colorado, USA.

[15] Parcels A. A novel framework for training and development utilizing value engineering methodology. MSc Thesis, Southern Illinois University Edwardsville, 2019. 